\title{
Endoscopic/Endobronchial Ultrasound-Guided Fine Needle Aspiration and Ancillary Techniques, Particularly Flow Cytometry, in Diagnosing Deep-Seated Lymphomas
}

\author{
Ming Jin Paul E. Wakely Jr. \\ Department of Pathology, The Ohio State University Wexner Medical Center, Columbus, Ohio, USA
}

\section{Key Words}

Ancillary techniques - Deep-seated lymphomas .

Endobronchial ultrasound - Endoscopic ultrasound · Fine needle aspiration · Flow cytometry

\begin{abstract}
Evaluation of deep-seated lymphomas by fine-needle aspiration (FNA) can be challenging due to their reduced accessibility. Controversy remains as to whether FNA and ancillary techniques can be used to diagnose deep-seated lymphomas reliably and sufficiently for clinical management. Most published studies are favorable that endobronchial ultrasound (EBUS)/endoscopic ultrasound (EUS)-FNA plays an important role in the diagnosis of deep-seated lymphomas. The addition of ancillary techniques, particularly flow cytometry, increases diagnostic yield. While subclassification is possible in a reasonable proportion of cases, the reported rates of successful subclassification are lower than those for lymphoma detection/diagnosis. The diagnostic limitation exists for Hodgkin's lymphoma, grading of follicular lymphoma, and some T-cell lymphomas. The role of FNA in deep-seated lymphomas is much better established for recurrent than primary disease. It remains unclear whether the use of large-sized-needle FNA or a combination of core
\end{abstract}

needle biopsy and FNA improves subclassification. It is important for cytopathologists to have considerable understanding of the WHO lymphoma classification and develop a collaborative working relationship with hematopathologists and oncologists. As EUS/EBUS-FNA techniques advance and sophisticated molecular techniques such as nextgeneration sequencing become possible, the role of FNA in the diagnosis of deep-seated lymphomas will possibly increase.

(c) 2016 S. Karger AG, Basel

\section{Introduction}

The evaluation of deep-seated lymphomas can be challenging. It often requires balancing diagnostic necessity versus the patient's general medical condition. Enlarged intrathoracic and intra-abdominal nodes present a unique challenge. Controversy remains as to whether endoscopic ultrasound (EUS)- and endobronchial ultrasound (EBUS)-guided fine needle aspiration (FNA) biopsy with ancillary studies, particularly flow cytometry (FC), can even be used to reliably diagnose deep-seated lymphomas such that the oncologists can proceed with appropriate clinical management.

\section{KARGER}

E-Mail karger@karger.com

www.karger.com/acy
(C) 2016 S. Karger AG, Basel

0001-5547/16/0604-0326\$39.50/0 


\section{Diagnostic Utility of EUS/EBUS-FNA}

Because of their location, specimen sampling from deep-seated lesions involves image guidance. Traditional procedural options include: percutaneous computed tomography (CT)- or ultrasound (US)-guided FNA; mediastinoscopy, video-assisted thoracoscopy, or open thoracotomy for tissue biopsies of intrathoracic lesions and laparoscopy or open laparotomy for tissue biopsies of intraabdominal lesions. The first comprehensive report on FNA diagnosis of deep-seated lymphomas (intra-abdominal and retroperitoneal), published in 1990, used percutaneous image-guided FNA [1]. All of these procedures are relatively invasive and associated with certain risks of complications. Some of these options are very costly as well.

US is one of the important discoveries of the 20th century, revolutionizing the field of diagnostic imaging [2]. Since the introduction of EUS in the early 1980s, it has progressed from a purely diagnostic tool to one that can be used to provide pathology samples (via FNA or core needle biopsy) as well as diverse therapeutic interventions [3-5]. EUS/EBUS-FNA has been shown to be a very useful, safe, and cost-effective modality for sampling deep-seated lesions. EBUS-FNA allows sampling from all bilateral mediastinal and hilar lymph node regions other than the aortopulmonary and para-aortic areas, covering a larger area than any single surgical procedure [6]. EUS-FNA is very useful for intra-abdominal and some intrathoracic deepseated lesions in close proximity to the gastrointestinal tract, and even for deep pelvic lesions sampled through the rectum that are relatively inaccessible by other standard image-guided techniques. Small lesions, as small as $5 \mathrm{~mm}$ in diameter, may be biopsied using EUS-FNA, which is not usually possible using other methods, including CT-guided biopsy or FNA $[7,8]$. In contrast to some of the traditional procedures, both EUS- and EBUS-FNA can be performed repeatedly for surveillance purposes. Mediastinoscopy nearly always leads to significant fibrosis; repeat procedures tend to be challenging and have a low diagnostic yield [9]. EUS/EBUS-FNA is well tolerated, avoiding exposure to radiation and general anesthesia associated with some other modalities [10-12]. Unlike many other techniques, it can be carried out in an outpatient setting using conscious sedation rather than general anesthesia. EUS/EBUS-FNA is also a safer modality compared to percutaneous CT- or US-guided FNA because of its higher spatial resolution and shorter needle tract to the target. The interposed vessels can be easily avoided by real-time imaging with EUS [13]. Cost analysis has shown that EBUS-FNA is 3- to 10 -fold less expensive than mediasti- noscopic tissue biopsy $[14,15]$. The limitations of EBUS/ EUS-FNA include inaccessibility to some areas such as the subdiaphragmatic region and the difficulty in obtaining useful samples from necrotic or calcified lesions.

\section{FNA Diagnosis of Lymphoma: Overview}

A large amount of literature exists emphasizing the significance of FNA diagnosis of lymphoma [16-18]. Many have demonstrated that FNA is highly accurate in the diagnosis and subclassification of some lymphomas, particularly non-Hodgkin's lymphomas (NHLs), that surgical biopsy may not always be necessary. However, the value of FNA diagnosis of lymphoma remains controversial. More than 10 years ago, an article by Hehn et al. [19] sparked worldwide controversy. This study suggested that FNA does not usually provide reliable diagnosis and perhaps may even be misleading.

One of the most cited drawbacks of FNA diagnosis of lymphoma is the loss of tissue architecture. However, many cytopathologists argue that in the current WHO (2008) lymphoma classification [20], the diagnosis and classification of lymphomas are based not only on their morphologic features, but also on their immunophenotypic, cytogenetic, and molecular profiles. Although the architecture is still important, not all the lymphoma classifications are solely dependent on it. The immunophenotypic, cytogenetic, and molecular studies can all be performed on the aspirated material.

The second most criticized limitation of FNA diagnosis of lymphoma is inadequate sampling. Insufficient or suboptimal sampling can be due to a number of factors, including the nature and size of the lesion, experience of the operator, number of passes, size of the FNA needle, availability of an on-site evaluation, preservation technique for ancillary studies, and most importantly the workflow. Optimizing an institutionally based workflow is imperative for suspected lymphomas and requires multidisciplinary coordination among radiologists, endoscopists, pathologists, and oncologists.

Another reason behind the difficulty of an FNA diagnosis of a specific lymphoma subtype is the inherent complexity of past and current lymphoma classifications [20]. Because of this existing complexity and a continuously growing list, many cytopathologists are not familiar/ comfortable enough with the various subclassifications. Thus, it is crucial for cytopathologists to keep updated with new developments in this field and to work closely with hematopathologists and a clinical team. 
Table 1. Literature Review: FNA Diagnosis of Deep-Seated Lymphomas

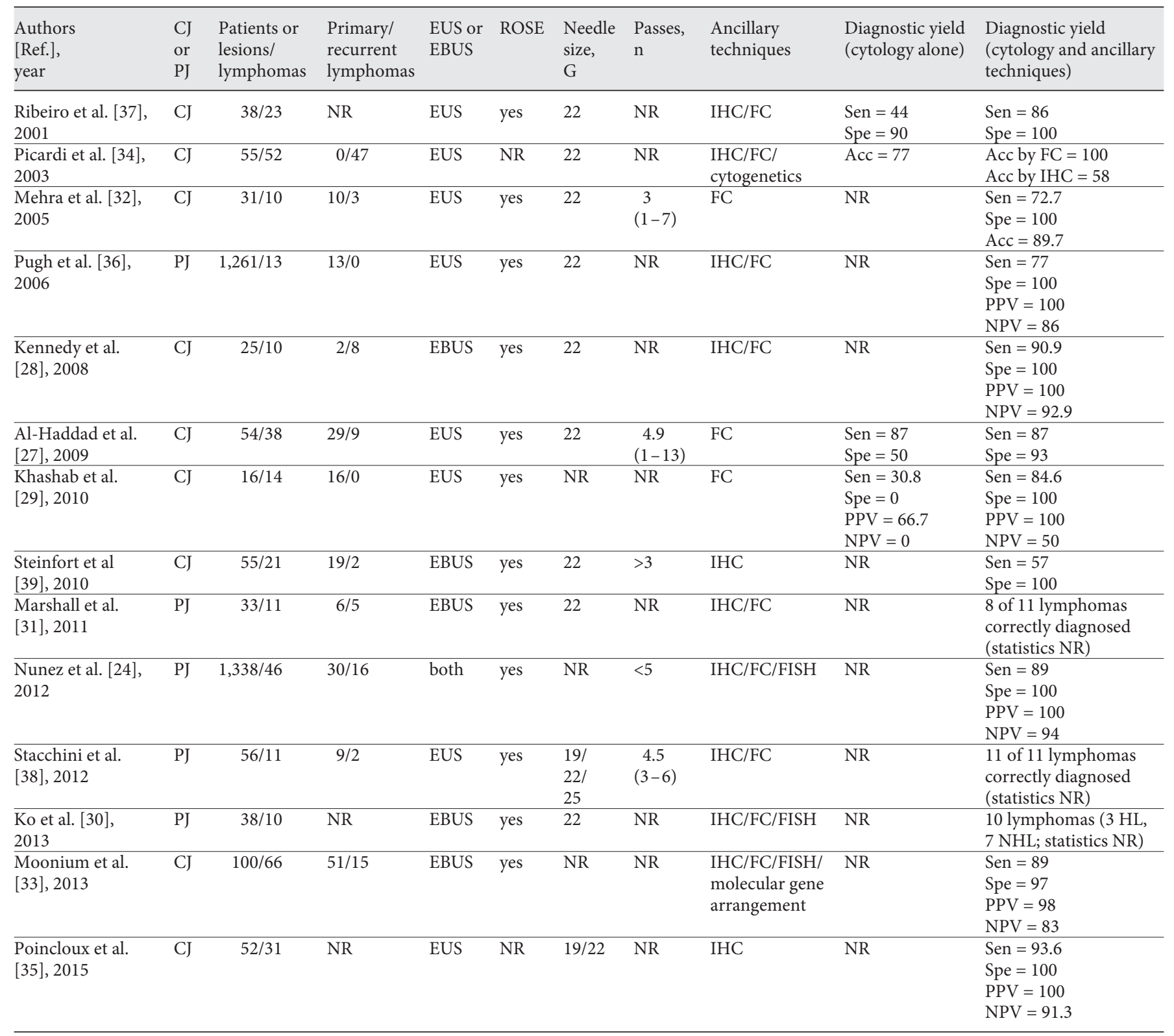

$\mathrm{CJ}=$ Clinical journal; $\mathrm{PJ}$ = pathology journal; $\mathrm{NR}$ = not reported; Sen = sensitivity; Spe = specificity; $\mathrm{PPV}=$ positive predictive value; $\mathrm{NPV}=$ negative predictive value; Acc = accuracy.

\section{FNA Diagnosis of Deep-Seated Lymphomas via EUS/EBUS, Emphasizing the Role of FC}

The progress of advanced diagnostic imaging has led to the increasing detection of enlarged intrathoracic or intra-abdominal lymph nodes. EUS- or EBUS-FNA has been demonstrated to be an accurate tool for the cytological diagnosis of deep-seated lesions of unknown ori- gin, especially metastatic epithelial malignancies $[13,21-$ 24]. However, FNA diagnosis of deep-seated lymphoma remains controversial $[6,25,26]$.

\section{Literature Review}

Table 1 summarizes 14 studies [24, 27-39] focused on the efficacy of the diagnosis of deep-seated lymphomas using EUS/EBUS-FNA from the past 15 years. A direct 
comparison among these studies is not possible because each study has a unique design with different definitions of 'gold standard', different statistical measures, and variable institutional workflows; nevertheless, they provide us a general overview of/progress in this field. Overall, most studies are favorable that EUS- or EBUS-FNA, in conjunction with ancillary techniques, plays an important role in the diagnosis of deep-seated lymphomas. Two thirds of the studies were published in clinical journals, and the rest in pathology journals. The number of patients/lesions ranged widely depending on study inclusion criteria. The number of lymphomas ranged from 7 to 66 , with 5 studies having $>30$ cases. Most studies included both nodal and extranodal sites. Most used a conventional 22-gauge needle with varying number of passes. Studies using only a 19-gauge needle or core biopsy were not included in this table. FNA smears stained with Romanowsky and Papanicolaou stain were used for cytomorphological evaluation. FC analysis was used more often (most studies) than any other ancillary techniques. Immunohistochemistry (IHC) stains were typically applied at the discretion of the cytopathologists. Cytogenetics or fluorescence in situ hybridization (FISH) was performed occasionally on selected cases (3 of 14). Molecular polymerase chain reaction (PCR) tests of B- or T-cell clonality gene arrangements were performed infrequently (1 of 14). Overall, the specificity of detection was consistently higher than sensitivity. The addition of ancillary techniques, mainly FC, increased the sensitivity considerably (84.6-87\%), as well as the specificity (93-100\%), compared with using cytomorphological evaluation alone (sensitivity and specificity ranging from 30.8 to 87 and from 0 to $100 \%$, respectively) $[27,29,37]$.

Rapid on-site evaluation (ROSE) was performed in almost all the studies listed in table 1 . There is no doubt that ROSE not only increases the overall diagnostic yield, but also effectively helps to triage the specimen for ancillary studies [40-42]. The value of ROSE is particularly more significant for deep-seated lymphomas than for other nonhematopoietic or superficial lesions.

\section{Cytomorphological Evaluation}

Cytomorphological evaluation made from smears is the first step in the diagnostic workup of deep-seated FNA. The determination of lineage differentiation is the beginning. The distinction of epithelial, lymphoid, or other lineages is usually not difficult for experienced cytopathologists because lymphoid cells are characterized by a predominantly single-cell pattern, whereas epithelial cells typically demonstrate cohesive clusters. The presence of abundant lymphoglandular bodies associated with predominant or lesional cells suggests a lymphoid process. In our institution, we prefer to stain smeared slides (80\%) with the Romanowsky stain (Diff-Quik) if a hematopoietic lineage is determined at the time of ROSE. However, the distinction may not always be straightforward $[43,44]$. Lymphoma cells may artificially show 'pseudocohesion', especially in highly cellular specimens, and some poorly differentiated nonlymphoid malignancy may show a predominant pattern of dispersion. Confounding factors such as fibrosis and necrosis as well as preparation artifacts may complicate the matter. In challenging cases, especially in the immediate evaluation, the determination should be made in correlation with clinical/radiological findings and cytomorphological features. Appropriate triage for ancillary techniques is also essential.

\section{Ancillary Technique: FC}

It has been well accepted that the addition of ancillary techniques, particularly FC, increases the diagnostic yield of deep-seated lymphomas. Among the studies listed in table 1, 12 of 14 used FC as an ancillary tool. The primary role of FC is to establish the B-lymphocyte clonality which may be difficult or impossible to do in some cases if the evaluation is based on cytomorphology alone. FC is also useful in subclassifying some lymphomas, especially when the IHC evaluation of cell blocks is not possible. FC is an imperfect tool. False-negative results are typically attributed to an insufficient amount of material, sampling error, or low viability due to the destruction of fragile cells, particularly in large-cell lymphomas. The presence of clonal B-cell populations in a nonlymphomatous process has occasionally been described where they appear to affect less than $1 \%$ of all reactive lymph nodes [45]. Aberrant expression may lead to confusion and an inability to correctly subtype some lymphomas. Opinions vary as to the indication of sending a specimen for FC and how much is enough. It is generally accepted that the aspirate material should be triaged to FC at the discretion of a cytopathologist taking into account cytomorphology, endoscopic impression, as well as clinical history. Nevertheless, some authors advocate that all specimens be sent for FC whenever there is clinical suspicion of lymphoma [26]. Nunez et al. [24] determined that two dedicated passes provided adequate cellularity (average of $5.66 \mathrm{mil}-$ lion cells) for FC analysis. With the new addition of more sophisticated 8-/10-color FC machines in some laboratories, it is expected that a diagnosis of lymphoma will be rendered on fewer cells, thus making FC an even more attractive ancillary tool. 
Table 2. Literature review: FNA diagnosis of deep-seated lymphomas emphasizing subclassification

\begin{tabular}{|c|c|c|c|c|c|c|}
\hline $\begin{array}{l}\text { Authors } \\
\text { [Ref.], year }\end{array}$ & $\begin{array}{l}\mathrm{CJ} \text { or } \\
\mathrm{PJ}\end{array}$ & $\begin{array}{l}\text { Lesions/ } \\
\text { lymphomas }\end{array}$ & $\begin{array}{l}\text { Primary/ } \\
\text { recurrent }\end{array}$ & $\begin{array}{l}\text { Needle size, } \\
\text { G }\end{array}$ & $\begin{array}{l}\text { Ancillary } \\
\text { techniques }\end{array}$ & $\begin{array}{l}\text { Subclassification } \\
\text { rate, } \%\end{array}$ \\
\hline $\begin{array}{l}\text { Nakahara et al. } \\
{[13], 2009}\end{array}$ & CJ & $57 / 12$ & NR & 22 & IHC & 83 \\
\hline $\begin{array}{l}\text { Riebeiro et al. } \\
{[49], 2010}\end{array}$ & CJ & $\mathrm{NR} / 24$ & NR & $\begin{array}{l}22 \text { (FNA) } \\
\text { and/or } 19 \\
\text { (core biopsy) }\end{array}$ & $\mathrm{IHC} / \mathrm{FC}$ & $\begin{array}{l}73.6 \text { for FNA; } \\
66.6 \text { for core biopsy }\end{array}$ \\
\hline $\begin{array}{l}\text { Steinfort et al. } \\
{[39], 2010}\end{array}$ & CJ & $55 / 21$ & $19 / 2$ & 22 & IHC & 57 \\
\hline $\begin{array}{l}\text { Yasuda et al. [50], } \\
2012\end{array}$ & CJ & $240 / 152$ & NR & mostly 19 & $\begin{array}{l}\text { IHC/FC/ } \\
\text { cytogenetics }\end{array}$ & 88.8 \\
\hline $\begin{array}{l}\text { Iqbal et al. } \\
\text { [48], } 2012\end{array}$ & CJ & NR/65 & $32 / 33$ & 21 & IHC/FISH & $\begin{array}{l}\text { Sen }=38 \text { (primary } \\
22 ; \text { recurrent 55) }\end{array}$ \\
\hline $\begin{array}{l}\text { Stacchini et al. } \\
{[38], 2012}\end{array}$ & $\mathrm{PJ}$ & $56 / 11$ & $9 / 2$ & $19 / 22 / 25$ & $\mathrm{IHC} / \mathrm{FC}$ & 72.7 \\
\hline $\begin{array}{l}\text { Moonim et al. } \\
{[33], 2013}\end{array}$ & CJ & $100 / 66$ & $51 / 15$ & NR & $\begin{array}{l}\mathrm{IHC} / \mathrm{FC} / \mathrm{FISH} / \\
\text { molecular gene } \\
\text { arrangement }\end{array}$ & $\begin{array}{l}\text { Sen of high-/low- } \\
\text { grade NHL/HL = } \\
90 / 100 / 79\end{array}$ \\
\hline $\begin{array}{l}\text { Poincloux et al. } \\
{[35], 2015}\end{array}$ & CJ & $52 / 31$ & NR & $19 / 22$ & IHC & 68 \\
\hline
\end{tabular}

\section{Ancillary Technique: Others}

IHC staining remains the most widely used ancillary technique when evaluating tissue sections for possible lymphoma; however, the scant cellularity and crush artifact on cell block sections may limit the use of IHC. Cytogenetics or FISH can be used to identify lymphomas with characteristic chromosomal translocations, including follicular lymphoma (FL) $[\mathrm{t}(14 ; 18)]$, mantle-cell lymphoma $[\mathrm{t}(11 ; 14)]$, Burkitt's lymphoma $[\mathrm{t}(8 ; 14)]$, and anaplastic T-cell lymphoma [ $t(2: 5)]$, for example. FISH testing can be performed on cell block sections as well as on cytology smears similar to tissue specimens [24, 46, 47]. Molecular PCR tests of B- and T-cell gene arrangement can be performed when the clonality by FC is inconclusive.

\section{Lymphoma Subclassification Using EUS/EUS-FNA}

The studies listed in table 1 demonstrate that if lymphoma is the cause of an undiagnosed deep-seated lymphadenopathy, at least its presence can be reliably detected by EUS/EBUS-FNA. However, many oncologists remain skeptical about the ability of FNA to accurately classify lymphomas and would consider an addi- tional tissue biopsy (excisional or core biopsy) as being necessary to answer specific prognostic and treatment questions.

\section{Literature Review}

Table 2 lists 8 studies investigating the role of FNA in the subclassification of deep-seated lymphomas in the past several years after the 2008 WHO classification [13, $33,35,38,39,48-50]$. Most studies were published in clinical journals. The number of lymphoma cases varied with 3 studies including more than 60 cases. Overall, the reported rates of successfully subclassified lymphomas were lower than those for the detection/diagnosis of lymphomas reported in table 1, ranging from 38 to $88.8 \%$. These rates varied widely, likely due to significant differences in case cohorts, study designs, and confirmatory method criteria for a definitive subclassification. Most studies concluded that subclassification was possible in a reasonable proportion of cases. Nakahara et al. [13] believed the results of cytology were equal to or better than histology because of the availability of on-site evaluation and the ability to sample a wide area. However, Iqbal et al. [48] reported a very low sensitivity of $38 \%$, suggesting that EBUS-FNA does not provide sufficient diagnostic material for subtyping. A study by Poincloux et al. [35] 
concluded that the successful rate of subclassification was significantly associated with target size $>30 \mathrm{~mm}$.

It is mostly accepted that the role of FNA in deep-seated lymphomas seems much better established in recurrent than in primary lymphomas $[33,34,48]$. In the setting of a recurrent lymphoma, a specific subclassification is often not needed to guide therapy.

\section{Inherent Limitations}

It is clear that EUS/EBUS-FNA does not allow the diagnosis of all lymphoma subtypes with equal performance. Some lymphoma types, such as chronic lymphocytic lymphoma and mantle-cell lymphoma, encompass characteristic cytological and immunophenotypic profiles to allow for acceptable diagnosis using FNA in conjunction with appropriate ancillary techniques. Several studies have addressed the diagnostic challenge in Hodgkin's lymphoma (HL) and suggested that tissue biopsy is still the procedure of choice [13, 33, 39, 49]. First, FNA specimens from HL (especially nodular sclerosing HL, the most common type) are usually hypocellular. Secondly, FC does not play a role in the diagnosis of this particular type of lymphoma due to the lack of a clonal population. Lastly, IHC stains performed on a cell block of HL are difficult to interpret due to the limited tissue/loss of architecture, rarity of Reed-Sternberg cells, and crush artifact. All these factors may contribute to a considerable false-negative rate. Another well-reported limitation is FL grading $[24,36,38,51]$. FL is one of the more frequently diagnosed lymphomas in deep-seated lymph nodes, and grading is considered a critical prognostic factor. Some authors state that adequate grading of FL is not possible on cytological material [19]. Differentiation between low-grade (grade 1 and 2) and high-grade (grade 3) lymphomas is clinically important and usually not difficult. The distinction between grade 1 and 2 is not easy, but it is not necessary clinically [20]. Also, differentiating largecell transformation of a FL from diffuse large B-cell lymphoma has little clinical impact. A diagnosis of large Bcell lymphoma of follicular center origin or large B-cell lymphoma not otherwise specified may be sufficient for clinical management [52]. Caution is required when focal large-cell transformation is present. It may not be possible to distinguish between grade 2 and 3 . A similar limitation applies when evaluating large-cell transformation of chronic lymphocytic/small-cell lymphomas. Of note, the side scatter value of FC analysis can aid in cell size evaluation in addition to cytomorphology. In addition, T-cell lymphomas are more difficult to diagnose and subclassify with EUS/EBUS-FNA. Although FC analysis is helpful in identifying an abnormal T-cell population, not all T-cell lymphomas have distinct immunophenotypes. T-cell receptor gene arrangements can be helpful in determining clonality, but the test may not be readily available, and the interpretation is not always straightforward.

\section{Role of Large Core Biopsy in Subclassification}

Since the usefulness of FNA has been questioned for lymphoma subclassification due to the lack of architecture and inadequate specimen sampling, the technique of EUSguided core needle biopsy using a larger needle size has been proposed as a possible solution. The most commonly used needle sizes for diagnostic FNA are 22 or even 25 $\mathrm{G}$. The primary larger needle types on the market include conventional 19-gauge, trucut (QuickCore ${ }^{\mathrm{TM}}$ ), and 19gauge ProCore ${ }^{\mathrm{TM}}$ needles. These larger needles seem to be better than smaller needles in obtaining an adequate coretissue sample for preserving histological architecture [5355]. They provide tissue fragments as opposed to single cells and cell groups, but require lymph nodes to be of a sufficient size to allow for sampling. The increased stiffness of the needles makes them more restrictive and difficult to maneuver [50]. Trucut needles do not perform well when the echoendoscope is not straight (e.g., duodenal bulb approach). Iglesias-Garcia et al. [53] have shown that the newer 19-gauge ProCore ${ }^{\mathrm{TM}}$ needles can overcome the drawbacks of the trucut needles. EUS-guided core needle biopsy or a combination of core needle biopsy and FNA has been shown to improve the diagnostic yield above that of FNA alone $[49,50,56]$. Gimeno-Garcia et al. [25] reviewed 5 studies that evaluated the ability of EUSguided needle biopsy to provide adequate samples for subclassification and showed that lymphoma diagnosis was achieved in $94 \%$ of cases; subclassification according to the $\mathrm{WHO}$ criteria was possible in $85 \%$ of cases. The incidence of complications associated with EUS-guided core biopsy was reported to be low (2.9\%). However, in a series comparing its use with FNA for a range of pathologies, no significant difference in yield was demonstrated, and one example of mediastinitis was encountered [57]. Al-Haddad et al. [27] used core needle biopsy in one of their patients, with no superiority over FNA in that case. Overall, it remains unclear whether the use of large-sized needles increases the diagnostic classification rate for lymphomas. Future technical improvements in these needles along with more evidence-based studies supporting their application in the diagnosis/subclassification of lymphomas might provide the balance we are seeking between using minimally invasive procedures and having sufficient architectural diagnostic information. It is worthwhile to note 
that the current WHO defining criteria are based largely on histological findings from surgically excised specimens and not on core needle biopsies. Although a core needle biopsy or a combination of core biopsy and FNA is almost certainly advantageous in selected cases, it may still be insufficient to fully subclassify some lymphomas.

\section{Role of Ancillary Techniques in Subclassification}

While the role of FC in establishing clonality to differentiate benign reactive processes is well recognized, the role of FC in lymphoma subclassification is probably similar to or not better than IHC stains. As mentioned earlier, side-scatter analysis from FC can help to determine the size of lymphoma cells in addition to cytomorphology, which is useful in cases of large-cell transformation. Some entities characterized by specific gene expression profiles or translocations can be accurately classified based on FNA material. For example, a panel of IHC stains of CD10, BCL-6, and MUM1 can subclassify diffuse large B-cell lymphomas into germinal-center B-cell-like and activated B-cell-like origin, which has significant prognostic impact. Also, FISH translocation analysis of MYC/BCL-2 can provide diagnostic evidence for Burkitt's and 'doublehit' lymphomas. However, many entities lack such features. In the studies listed in tables 1 and 2, only occasional studies used cytogenetics/FISH. On the other hand, cytogenetic/FISH/molecular studies are notalways necessary in subtyping. Mantle-cell lymphoma can be definitively diagnosed by IHC stains of BCL-1/cyclin D1/SOX-11 [58]. FISH testing $(11 ; 14)$ may not be necessary. The establishment of clonality by PCR gene arrangements is only needed when diagnosis is insufficient/indeterminate by cytomorphology, FC, or IHC. In the future, next-generation sequencing using FNA material may have a potential impact on classifying lymphomas [59], similar to nonhematopoietic malignancies [60]. Studies have shown that FNA material has the advantage of providing higher-quality DNA. Many studies have demonstrated that cytogenetics as well as newer molecular techniques can be performed on smear specimens [24, 46, 47].

\section{FNA Diagnosis of Specific Organ-Based Primary Deep-Seated Lymphomas}

The most commonly reported organ-based, deepseated lymphoma type using these techniques is primary pancreatic lymphoma (PPL). PPLs are rare and represent less than $0.5 \%$ of all pancreatic neoplasms [61]. Most are intermediate or high-grade NHL, with diffuse large B-cell lymphomas being the predominate type. They typically have a much better prognosis than adenocarcinoma of the pancreas. Because the management and outcome of PPLs are completely different from pancreatic epithelial neoplasms, accurate recognition of these rare tumors is essential. Several case series and considerable case reports have demonstrated that the diagnosis and further classification of PPLs using EUS-FNA is possible [29, 62-64].

Clinical features suggestive of PPLs include: a previous history of lymphoma, relatively young age, presence of $\mathrm{B}$ symptoms, large tumor size, low CA 19-9 level, and absence of jaundice. Typically, EUS shows a large heterogeneous mass [63]. Despite the larger size at presentation, it is less likely to be associated with pancreatic duct dilation and vascular invasion $[62,63]$. Malignant-appearing lymphadenopathy is significantly more common in PPLs than in adenocarcinomas [62]. Similar to lymphomas elsewhere, the most important cytomorphological clue to the diagnosis is a cellular aspirate with mostly dyshesive cells with scant cytoplasm and associated with abundant lymphoglandular bodies. Necrosis and fibrosis may obscure the cellularity and cause interpretive difficulty in high-grade cases. A low-grade lymphoid process can be difficult to differentiate from inadvertently sampled lymph nodes or chronic inflammation. ROSE is essential for procurement/triage of additional material for FC, cell block, and molecular studies. Studies have shown that a combination of FC and other ancillary studies increase the sensitivity and specificity. The diagnostic accuracy is particularly improved with the addition of FC $[62,63]$.

In contrast to the pancreas, lymphoma is a major cause of splenic tumors [65]. Percutaneous US-guided FNA has been considered an effective and less invasive alternative to surgical splenectomy for the diagnosis of lymphoma [66-68]. However, the use of this diagnostic technique remains controversial. EUS provides a good image of the spleen through the gastric wall. Studies have demonstrated that transgastric EUS-FNA is a useful and safe tool, and may be easier than the percutaneous approach $[69,70]$.

Other organ-based, deep-seated lymphomas diagnosed by FNA are much less common, and the reported organ sites include liver, kidney, luminal gastrointestinal tract, and mediastinum.

\section{Conclusion}

EUS/EBUS-FNA plays an important role in the diagnosis of deep-seated lymphomas. The addition of ancillary techniques, particularly FC, increases the diagnostic 
yield. While studies have shown that subclassification is possible in a reasonable proportion of cases, the reported rates of successful subclassification are lower than those for lymphoma detection/diagnosis. EUS/EBUS-FNA does not allow for the diagnosis of all lymphoma subtypes with equal performance. Diagnostic limitation exists particularly for HL, grading of FL, and some T-cell lymphomas. It remains unclear whether the use of large-sized needles or a combination of core needle biopsy plus FNA improves the subclassification. As EUS/EBUS-FNA techniques advance and more molecular techniques such as next-generation sequencing become possible for FNA material, the reliability of FNA diagnosis in deep-seated lymphomas will continue to improve.
While many general approaches to FNA diagnosis of superficial lymphomas apply equally to deep-seated lymphomas, the deep location makes it unique and challenging. Currently, most centers in North America require an excisional biopsy for suspected primary superficial lymphoma. However, for deep-seated lymphadenopathy, an FNA diagnosis of B- or T-cell lymphoma not otherwise specified may suffice for therapeutic management depending on the patient's general condition/comorbidity. Mutual collaboration and cooperation between cytopathologists and hematopathologists in the advancement of the FNA-based diagnosis of deep-seated lymphomas cannot be underestimated.

\section{References}

1 Cafferty LL, Katz RL, Ordonez NG, Carrasco $\mathrm{CH}$, Cabanillas FR: Fine needle aspiration diagnosis of intraabdominal and retroperitoneal lymphomas by a morphologic and immunocytochemical approach. Cancer 1990;65: 72-77.

- 2 Hussain T, Salamat A, Farooq MA, Hassan F, Hafeez M: Indications for endoscopic ultrasound and diagnosis on fine-needle aspiration and cytology. J Coll Physicians Surg Pak 2009; 19:223-227.

3 DiMagno EP, Buxton JL, Regan PT, Hattery RR, Wilson DA, Suarez JR, Green PS: Ultrasonic endoscope. Lancet 1980;1:629-631.

-4 Eltoum IA, Alston EA, Roberson J: Trends in pancreatic pathology practice before and after implementation of endoscopic ultrasoundguided fine-needle aspiration: an example of disruptive innovation effect? Arch Pathol Lab Med 2012;136:447-453.

5 Tarantino I, Barresi L: Interventional endoscopic ultrasound: therapeutic capability and potential. World J Gastrointest Endosc 2009; 1:39-44.

6 Navani N, Janes SM: Endobronchial ultrasound-guided transbronchial needle aspiration for lymphoma: the final frontier. Am J Respir Crit Care Med 2013;188:1183-1185.

7 Barawi M, Gress F: EUS-guided fine-needle aspiration in the mediastinum. Gastrointest Endosc 2000;52(suppl 6):S12-S17.

8 Jhala NC, Jhala D, Eltoum I, Vickers SM, Wilcox CM, Chhieng DC, Eloubeidi MA: Endoscopic ultrasound-guided fine-needle aspiration biopsy: a powerful tool to obtain samples from small lesions. Cancer 2004;102:239-246.

-9 Herth FJ, Annema JT, Eberhardt R, Yasufuku K, Ernst A, Krasnik M, Rintoul RC: Endobronchial ultrasound with transbronchial needle aspiration for restaging the mediastinum in lung cancer. J Clin Oncol 2008;26: 3346-3350.
10 Moehler M, Voigt J, Kastor M, Heil M, Sengespeick C, Biesterfeld S, Dippold W, Kanzler S, Galle PR: Endoscopic ultrasonographyguided fine-needle aspiration (EUS-FNA) as primary diagnostic tool for unclear lesions in the upper gastrointestinal tract (in German). Dtsch Med Wochenschr 2011;136:303-308.

-11 Yasuda I, Tsurumi H, Omar S, Iwashita T, Kojima Y, Yamada T, Sawada M, Takami T, Moriwaki H, Soehendra N: Endoscopic ultrasound-guided fine-needle aspiration biopsy for lymphadenopathy of unknown origin. Endoscopy 2006;38:919-924.

$\checkmark 12$ Yusuf A, Khalid SR, Ahmed Q, Faruqui ZS: Endoscopic ultrasound guided biopsy of a mediastinal mass. J Ayub Med Coll Abbottabad 2004;16:72-73.

13 Nakahara O, Yamao K, Bhatia V, Sawaki A, Mizuno N, Takagi T, Shimizu Y, Koshikawa T, Yatabe Y, Baba H: Usefulness of endoscopic ultrasound-guided fine needle aspiration (EUS-FNA) for undiagnosed intra-abdominal lymphadenopathy. J Gastroenterol 2009; 44:562-567.

-14 Medford AR, Agrawal S, Free CM, Bennett JA: A performance and theoretical cost analysis of endobronchial ultrasound-guided transbronchial needle aspiration in a UK tertiary respiratory centre. QJM 2009;102:859864.

15 Bango A, Luyando L, Pandiella JR, et al: Bronchoscopic needle aspiration and biopsy of paratracheal tumors and hilar and mediastinal lymph nodes: security yield and cost-effectiveness. J Bronchol 2003;10:183-188.

16 Caraway NP: Evolving role of FNA biopsy in diagnosing lymphoma: past, present, and future. Cancer Cytopathol 2015;123:389-393.

17 Wakely PE Jr: The diagnosis of non-Hodgkin lymphoma using fine-needle aspiration cytopathology: a work in progress. Cancer Cytopathol 2010;118:238-243.
18 Zeppa P, Marino G, Troncone G, Fulciniti F, De Renzo A, Picardi M, Benincasa G, Rotoli B, Vetrani A, Palombini L: Fine-needle cytology and flow cytometry immunophenotyping and subclassification of non-Hodgkin lymphoma: a critical review of 307 cases with technical suggestions. Cancer 2004;102:5565.

19 Hehn ST, Grogan TM, Miller TP: Utility of fine-needle aspiration as a diagnostic technique in lymphoma. J Clin Oncol 2004;22: 3046-3052.

20 Swerdlow SH, Campo E, Harris NL, Jaffe ES, Pileri SA, Stein H, Thiele J, Vardiman JW (eds): World Health Organization Classification of Tumours of Haematopoietic and Lymphoid Tissues. Lyon, IARC Press, 2008.

21 Korenblit J, Anantharaman A, Loren DE, Kowalski TE, Siddiqui AA: The role of endoscopic ultrasound-guided fine needle aspiration (EUS-FNA) for the diagnosis of intraabdominal lymphadenopathy of unknown origin. J Interv Gastroenterol 2012;2:172176.

22 Loya A, Nadeem M, Yusuf MA: Use of ancillary techniques in improving the yield of samples obtained at endoscopic ultrasound-guided fine needle aspiration of thoracic and abdominal lymph nodes. Acta Cytol 2014;58: 192-197.

23 Mehmood S, Loya A, Yusuf MA: Clinical utility of endoscopic ultrasound-guided fineneedle aspiration in the diagnosis of mediastinal and intra-abdominal lymphadenopathy. Acta Cytol 2014;57:436-442.

24 Nunez AL, Jhala NC, Carroll AJ, Mikhail FM, Reddy VV, Xian RR, Jhala DN: Endoscopic ultrasound and endobronchial ultrasoundguided fine-needle aspiration of deep-seated lymphadenopathy: analysis of 1,338 cases. Cytojournal 2012;9:14. 
-25 Gimeno-Garcia AZ, Elwassief A, Paquin SC, Sahai AV: Endoscopic ultrasound-guided fine needle aspiration cytology and biopsy in the evaluation of lymphoma. Endosc Ultrasound 2012;1:17-22.

-26 Kwan V, Gottlieb D: Endoscopic ultrasoundfine needle aspiration for the diagnosis of lymphoma: are we there yet? J Gastroenterol Hepatol 2009;24:1808-1809.

-27 Al-Haddad M, Savabi MS, Sherman S, McHenry L, Leblanc J, Cramer H, Emerson R, O’Neil J, Khashab M, Dewitt J: Role of endoscopic ultrasound-guided fine-needle aspiration with flow cytometry to diagnose lymphoma: a single center experience. J Gastroenterol Hepatol 2009;24:1826-1833.

28 Kennedy MP, Jimenez CA, Bruzzi JF, Mhatre AD, Lei X, Giles FJ, Fanning T, Morice RC, Eapen GA: Endobronchial ultrasound-guided transbronchial needle aspiration in the diagnosis of lymphoma. Thorax 2008;63:360365.

29 Khashab M, Mokadem M, DeWitt J, Emerson R, Sherman S, LeBlanc J, McHenry L, AlRashdan A, Al-Haddad M: Endoscopic ultrasound-guided fine-needle aspiration with or without flow cytometry for the diagnosis of primary pancreatic lymphoma - a case series. Endoscopy 2010;42:228-231.

- 30 Ko HM, da Cunha Santos G, Darling G, Pierre A, Yasufuku K, Boerner SL, Geddie WR: Diagnosis and subclassification of lymphomas and non-neoplastic lesions involving mediastinal lymph nodes using endobronchial ultrasound-guided transbronchial needle aspiration. Diagn Cytopathol 2013;41:1023-1030.

- 31 Marshall CB, Jacob B, Patel S, Sneige N, Jimenez CA, Morice RC, Caraway N: The utility of endobronchial ultrasound-guided transbronchial needle aspiration biopsy in the diagnosis of mediastinal lymphoproliferative disorders. Cancer Cytopathol 2011;119:118126.

32 Mehra M, Tamhane A, Eloubeidi MA: EUSguided FNA combined with flow cytometry in the diagnoses of suspected or recurrent intrathoracic or retroperitoneal lymphoma. Gastrointest Endosc 2005;62:508-513.

- 33 Moonim MT, Breen R, Fields PA, Santis G: Diagnosis and subtyping of de novo and relapsed mediastinal lymphomas by endobronchial ultrasound needle aspiration. Am J Respir Crit Care Med 2013;188:1216-1223.

-34 Picardi M, Del Vecchio L, De Renzo A, Zeppa P, Luciano L, Rotoli B: Ultrasound-guided fine needle aspiration cytology combined with flow cytometric immunophenotyping for rapid characterization of deep-seated non-Hodgkin's lymphoma recurrence. Haematologica 2003;88:356-358.

-35 Poincloux L, Andre M, Darcha C, Goutte M, Dapoigny M, Bommelaer G, Abergel A, Tournilhac O: Usefulness of EUS-guided fine needle aspiration biopsy in the diagnosis of suspected or recurring lymphoproliferative disorders. Surg Oncol 2015, Epub ahead of print.
36 Pugh JL, Jhala NC, Eloubeidi MA, Chhieng DC, Eltoum IA, Crowe DR, Varadarajulu S, Jhala DN: Diagnosis of deep-seated lymphoma and leukemia by endoscopic ultrasoundguided fine-needle aspiration biopsy. Am J Clin Pathol 2006;125:703-709.

37 Ribeiro A, Vazquez-Sequeiros E, Wiersema LM, Wang KK, Clain JE, Wiersema MJ: EUSguided fine-needle aspiration combined with flow cytometry and immunocytochemistry in the diagnosis of lymphoma. Gastrointest Endosc 2001;53:485-491.

38 Stacchini A, Carucci P, Pacchioni D, Accinelli G, Demurtas A, Aliberti S, Bosco M, Bruno M, Balbo Mussetto A, Rizzetto M, et al: Diagnosis of deep-seated lymphomas by endoscopic ultrasound-guided fine needle aspiration combined with flow cytometry. Cytopathology 2012;23:50-56.

39 Steinfort DP, Conron M, Tsui A, Pasricha SR, Renwick WE, Antippa P, Irving LB: Endobronchial ultrasound-guided transbronchial needle aspiration for the evaluation of suspected lymphoma. J Thorac Oncol 2010;5: 804-809.

40 Ecka RS, Sharma M: Rapid on-site evaluation of EUS-FNA by cytopathologist: an experience of a tertiary hospital. Diagn Cytopathol 2013;41:1075-1080.

41 Mehmood S, Jahan A, Loya A, Yusuf MA: Onsite cytopathology evaluation and ancillary studies beneficial in EUS-FNA of pancreatic, mediastinal, intra-abdominal, and submucosal lesions. Diagn Cytopathol 2015;43:278286.

42 Schmidt RL, Walker BS, Howard K, Layfield LJ, Adler DG: Rapid on-site evaluation reduces needle passes in endoscopic ultrasoundguided fine-needle aspiration for solid pancreatic lesions: a risk-benefit analysis. Dig Dis Sci 2013;58:3280-3286.

43 Gangopadhyay M, Bhattacharyya NK, Ray S, Chakrabarty S, Pandit N: Guided fine needle aspiration cytology of retroperitoneal masses - our experience. J Cytol 2011;28:20-24.

44 Mohiuddin Y, Hong H, Juskevicius R: Cytological features of diffuse large B-cell lymphoma can mimic metastatic carcinoma on fine needle aspiration cytology. Cytopathology 2013;24:340-342.

45 Cozzolino I, Nappa S, Picardi M, De Renzo A, Troncone G, Palombini L, Zeppa P: Clonal Bcell population in a reactive lymph node in acquired immunodeficiency syndrome. Diagn Cytopathol 2009;37:910-914.

46 Bentz JS, Rowe LR, Anderson SR, Gupta PK, McGrath CM: Rapid detection of the $t(11 ; 14)$ translocation in mantle cell lymphoma by interphase fluorescence in situ hybridization on archival cytopathologic material. Cancer 2004;102:124-131.
47 Richmond J, Bryant R, Trotman W, Beatty B, Lunde J: FISH detection of $t(14 ; 18)$ in follicular lymphoma on Papanicolaou-stained archival cytology slides. Cancer 2006;108:198204.

-48 Iqbal S, DePew ZS, Kurtin PJ, Sykes AM, Johnson GB, Edell ES, Habermann TM, Maldonado F: Endobronchial ultrasound and lymphoproliferative disorders: a retrospective study. Ann Thorac Surg 2012;94:18301834.

49 Ribeiro A, Pereira D, Escalon MP, Goodman M, Byrne GE Jr: EUS-guided biopsy for the diagnosis and classification of lymphoma. Gastrointest Endosc 2010;71:851-855.

50 Yasuda I, Goto N, Tsurumi H, Nakashima M, Doi S, Iwashita T, Kanemura N, Kasahara S, Adachi S, Hara T, et al: Endoscopic ultrasound-guided fine needle aspiration biopsy for diagnosis of lymphoproliferative disorders: feasibility of immunohistological, flow cytometric, and cytogenetic assessments. Am J Gastroenterol 2012;107:397-404.

51 Creemers K, van der Heiden O, Los J, van Esser J, Newhall D, Djamin RS, Aerts JG: Endoscopic ultrasound fine needle aspiration in the diagnosis of lymphoma. J Oncol 2011;2011: 785425.

52 Young NA: Grading follicular lymphoma on fine-needle aspiration specimens - a practical approach. Cancer 2006;108:1-9.

53 Iglesias-Garcia J, Poley JW, Larghi A, Giovannini M, Petrone MC, Abdulkader I, Monges G, Costamagna G, Arcidiacono P, Biermann $\mathrm{K}$, et al: Feasibility and yield of a new EUS histology needle: results from a multicenter, pooled, cohort study. Gastrointest Endosc 2011;73:1189-1196.

54 Levy MJ, Jondal ML, Clain J, Wiersema MJ: Preliminary experience with an EUS-guided trucut biopsy needle compared with EUSguided FNA. Gastrointest Endosc 2003;57: 101-106.

55 Song TJ, Kim JH, Lee SS, Eum JB, Moon SH, Park DY, Seo DW, Lee SK, Jang SJ, Yun SC, et al: The prospective randomized, controlled trial of endoscopic ultrasound-guided fineneedle aspiration using $22 \mathrm{G}$ and $19 \mathrm{G}$ aspiration needles for solid pancreatic or peripancreatic masses. Am J Gastroenterol 2010;105: 1739-1745.

56 Eloubeidi MA, Mehra M, Bean SM: EUSguided 19-gauge trucut needle biopsy for diagnosis of lymphoma missed by EUS-guided FNA. Gastrointest Endosc 2007;65:937-939.

57 Varadarajulu S, Fraig M, Schmulewitz N, Roberts S, Wildi S, Hawes RH, Hoffman BJ, Wallace MB: Comparison of EUS-guided 19-gauge Trucut needle biopsy with EUSguided fine-needle aspiration. Endoscopy 2004;36:397-401.

58 Wakely PE: Mantle cell lymphoma: a report of 31 nodal and extranodal fine-needle aspirates. J Am Soc Cytopathol 2015;4:307-312.

-59 Slack GW, Gascoyne RD: Next-generation sequencing discoveries in lymphoma. Adv Anat Pathol 2013;20:110-116. 
60 Kanagal-Shamanna R, Portier BP, Singh RR, Routbort MJ, Aldape KD, Handal BA, Rahimi H, Reddy NG, Barkoh BA, Mishra BM, et al: Next-generation sequencing-based multigene mutation profiling of solid tumors using fine needle aspiration samples: promises and challenges for routine clinical diagnostics. Mod Pathol 2014;27:314-327.

61 Saif MW: Primary pancreatic lymphomas. JOP 2006;7:262-273.

62 Johnson EA, Benson ME, Guda N, Pfau PR, Frick TJ, Gopal DV: Differentiating primary pancreatic lymphoma from adenocarcinoma using endoscopic ultrasound characteristics and flow cytometry: a case-control study. Endosc Ultrasound 2014;3:221-225.
63 Ramesh J, Hebert-Magee S, Kim H, Trevino J, Varadarajulu S: Frequency of occurrence and characteristics of primary pancreatic lymphoma during endoscopic ultrasound guided fine needle aspiration: a retrospective study. Dig Liver Dis 2014;46:470-473.

64 Volmar KE, Routbort MJ, Jones CK, Xie HB: Primary pancreatic lymphoma evaluated by fine-needle aspiration: findings in 14 cases. Am J Clin Pathol 2004;121:898-903.

65 Civardi G, Vallisa D, Berte R, Giorgio A, Filice C, Caremani M, Caturelli E, Pompili M, De Sio I, Buscarini E, et al: Ultrasound-guided fine needle biopsy of the spleen: high clinical efficacy and low risk in a multicenter Italian study. Am J Hematol 2001;67:93-99.

66 Friedlander MA, Wei XJ, Iyengar P, Moreira AL: Diagnostic pitfalls in fine needle aspiration biopsy of the spleen. Diagn Cytopathol 2008;36:69-75.
67 Handa U, Tiwari A, Singhal N, Mohan H, Kaur R: Utility of ultrasound-guided fineneedle aspiration in splenic lesions. Diagn Cytopathol 2013;41:1038-1042.

68 Kumar PV, Monabati A, Raseki AR, Arshadi C, Malek-Hosseini SA, Talei AR, Sadeghi E: Splenic lesions: FNA findings in 48 cases. Cytopathology 2007;18:151-156.

69 Eloubeidi MA, Varadarajulu S, Eltoum I, Jhala D, Chhieng DC, Jhala NC: Transgastric endoscopic ultrasound-guided fine-needle aspiration biopsy and flow cytometry of suspected lymphoma of the spleen. Endoscopy 2006;38: 617-620.

70 Iwashita T, Yasuda I, Tsurumi H, Goto N, Nakashima M, Doi S, Hirose Y, Takami T, Moriwaki $\mathrm{H}$ : Endoscopic ultrasound-guided fine needle aspiration biopsy for splenic tumor: a case series. Endoscopy 2009;41:179-182. 